\title{
Research On Technical Barriers to Trade in Chinese Exports
}

\author{
Yao Yao ${ }^{\mathrm{a}}$, Yizhen Zhou ${ }^{\mathrm{b} *}$ and Jiangping $\mathrm{Zhu}^{\mathrm{c}}$ \\ Hangzhou Institute of Service Engineering, Hangzhou Normal University, Hangzhou, 311121, China \\ *Corresponding author.Email.:ayyaoexist@163.com, ${ }^{\text {bdreamerzhou@hotmail.com, }{ }^{c} y z-z j p @ h o t m a i l . c o m}$
}

\begin{abstract}
This paper analyzed technical barriers for China's exports, from the perspective of different types of technical barriers, in different industries and in different countries, and examined the impact and coping strategy of technical barriers. Agricultural export from China encountered technical barriers for the reason of food security, based on SPS and regulation of import countries. Strategic industry encountered intellectual property barriers. Manufacturing exports is under scrutiny for personal and health safety. In European Union, RAPEX and RASFF hold higher standards than other regions. In the United States, FDA warned against certain food products, medical supplies and clinical appliances exported from China; CPSC recalled Chinese products for product quality and safety; 337 investigations emphasized on infringement of patent rights. Japan and other developed countries also recalled or notified warnings against manufacturing goods for safety and food products for pollution. With its discrimination feature, the negative impact of technical barriers could lead to distortion of trade and welfare, and impair economic growth in the long run. Coping strategies, such as warning system, legal expertise and technical support, cooperation amongst trade partners, could help mitigate technical barriers and facilitate international trade.
\end{abstract}

Keywords: Technical barrier, International trade, Impact, Strategy.

\section{INTRODUCTION}

The rapid development in global trade contributes to economic growth and welfare benefit in all participants, especially the developing countries. However the disparity of distribution of the profit from global trade in different countries could lead to tensions in international trade, could prompt protectionism policies to maximize trade benefit at the cost of loss in trade partners. International trade barriers have the forms of tariff and non-tariff barriers. Non-tariff barriers are more flexible, could be applied to target specific country, industry or product, which has been used more frequently in international trade after the international financial crisis. Other than import quota, anti-dumping, anti-subsidy and other traditional non-tariff measure, this study analyzes the technical barrier, the rest of the paper is organized as follows: the second part analyzes different kinds of technical barriers in different industries; the third part illustrates technical barrier to trade in different destinations; the fourth part examines the impact of technical barriers on trade and economic growth, and provides coping strategy and policy; then the last part concludes.

\section{ANALYSIS OF TECHNICAL BARRIERS TO TRADE BY INDUSTRY}

Technical barriers have profound influence on export of Chinese agricultural products. SPS, Application of Sanitary and Phytosanitary Measures, is a multilateral agreement of WTO for global food security, which stipulated food safety and animal and plant health measures. On one hand, the SPS measures promote standardization of agriculture products in China, and enhance food security. On the other hand, the SPS measure increased costs in agriculture produce, lowered the profit margin, reduced competitiveness and elevated difficulty in export. The SPS measures taken upon Chinese products are initiated by both developed countries and developing countries. The impact of SPS measures covered almost all products, all destinations and all firms in Chinese agricultural export. The seafood export from Zhejiang Province to European Union has higher than standard chloromycetin level, while tea export has higher pesticide than standard level. The unregulated administration of pesticide and other chemicals lead to lower than standards agricultural export 
products. Moreover, for food security purpose, as strategic industry for a country, agriculture receives more protection from government in international trade than other industries.

For manufacture industry, trade partners enforced technical barriers in textile, electrical equipment, children's toy and other export products from China. Export of Children's toys is one of the industries faces the most frequent technical barrier. Lack of brand or design, less than sufficient quality control, low level of safety awareness and lack of unified industry standard enforcement, makes toy export more vulnerable to technical barriers. The complex and complicated technical barriers in toy industry take form of physical requirement, chemical safety, electrical safety, label and certification. Large quantity of toys recalled and returned caused direct loss, as well as indirect loss, which could harm the reputation of the industry. The intensifying competition in manufacture industry also attribute to technical barrier measures. Trade tension leads to enforced trade barriers to protect trade profit at national level.

In high-tech industry, technical barriers are more disguised and complicated. The globally unified standard for technical barrier in high-tech industry is still under discussion. In the era of knowledge economy and globalization, innovation in an economy requires research and development internationalization. Technical barrier hinders the communication of technology across borders. Weak property right protection in domestic market is the internal reason for property right barrier. However, the increasing competitiveness of high-tech products, such as electronics and information technology from Chinese firms, posed threat to profit of developed countries, which imposed property rights barrier for trade protectionism. Article 337 investigation of United States International Trade Commission is launched on some high-tech Chinese corporations, such as Huawei Technology Corporate and Haier Group. Increasing numbers of 337 investigations are launched against information technology export from China. Exclusive patent laws, misused property rights protection and various forms of technical barriers could target Chinese high-tech products specifically. European Union applied TRIP measures excessively to curtail Chinese high-tech export and protect local industry. Different types of technical barrier include technical standards, health quarantine and package and label of merchandise.

\section{TECHNICAL BARRIERS TO TRADE IN DIFFERENT COUNTRIES}

\subsection{Technical Barriers to Trade in European Union}

Technical barrier targeted Chinese export in European Union is increasing in the past decade, and involved various industries. In non-food industry, RAPEX, namely Rapid Alert System for non-food consumer products, was introduced in European Union as consumer safety alert, which was prevalently applied as technical barrier for non-food export products. In food industry, RASFF, namely Rapid Alert System for Food and Feed, is introduced to set up standards for food products, which could be used against Chinese food products in the European Union market. The standard stipulated in RAPEX and RASFF is revised over the time, for example, the RAPEX standard for toiletry was revised to a higher standard in 2017. In the year 2019, various food contact products from China are warned by RASFF, consequently withdrawn from European market, or prohibited entry and sealed by custom, such as kitchen knives and egg whisk. Export products from China warned by RAPEX in 2019 are mostly in the industry of children's toys, children's seats, children's clothes, and small electrical appliances such as USB chargers, electric outlet, LED lights, and hair dryers. The most affected industry is the toys products, which comprises large proportion of the warnings issued by European Union. The reasons for the warnings of children's toys and other products are: toxic substance, chocking risk, asphyxiation risk, burn, biochemistry hazard, bodily injury, impaired hearing and vision. While the toxic chemical problem has been dealt with by Chinese exporters, the risk of choking is used more frequently in recent years. Stretching rope, toxic substance, bodily injury, falling widget are the reasons for warning in children's clothes and other clothes. The reasons for the warnings of small electric appliances are: risk of electric shock, fire risk and burn.

\subsection{Technical Barriers to Trade in the United States}

Food and Drug Administration of the United States issued warnings against Chinese export in the area of food products, medical materials and supplies and other health related products. For food products, FDA warnings against Chinese products are mostly based on the reasons of excessive pesticide residual, unclean production environment. Vegetable products were denied entry for pesticide residual, for example, different batches of spinach paste and dried spinach are banned multiple times in 2019. Fruit products are denied import for unclean production environment, for example, peach juice and pears are denied entry in September 2019. For medical materials, supplies and other health related products, the reasons for FDA warnings are not in the 501(j) list or failure to provide information according to 501(j) / 501(k) list; inconsistency between product quality and product description; low quality or flawed products; fail to provide approval application; without FDA approval, fail to provide information required by FDA, or fail to register with FDA requirements; wrong label tag; unclean production environment, etc. The top 
reason of FDA warning is the compliance of the 501(j) list, either not in the list or fail to provide information according to 501(j) /501(k) list. The products denied entry based on this reason in year 2019 include: portable stretcher, resin dental adhesive, therapeutic electric massager, surgical instruments and materials, prescription lenses, disposable Mueller, implantable drug-supplying device, wound dressing bag, non-inflatable tourniquet, mercury thermometer, portable oxygen generator, spinal fixation implants, dental implants, otolaryngological syringe, ceramic orthodontic bracket, infusion device, etc. Lack of FDA approval is also frequently used, products denied import for the reasons of not approved by FDA or fail to register with FDA requirements include: self-expanding colonic metallic stent, dental root canal file, blood transfusion set, electronic Powered Wheelchair, pharmaceutical necessities, ultrasound pulse-echo scanner, surgical stapler, lumbar orthosis, adhesive bandage, etc. Levofloxacin produced in Jiangsu Province is denied by FDA for failure to provide approved application for new medicine. Other reasons are poor production and problems in label and production descriptions, include denied sphygmomanometer from China multiple times, for inconsistency between product quality and product description; electronic Powered Wheelchair, for mistaken label tag; catheter, for falsified trademark; non-absorbable gauze, for unclean production environment; polyethylene inspection glove, for low quality and flaws.

Some Chinese export products are recalled by Consumer Product Safety Committee (CPSC) for production safety concern, which caused huge amount of financial loss for Chinese exporters. Pajamas with famous Chinese brand were recalled for inflammable risk in September, 2019. Dehumidification machine of famous Chinese brand were recalled for fire risk in July, 2019. Motorcycles were recalled multiple times for fire risk and burn risk. Children's toys and other products were recalled for chocking risk and other safety concern. Electronic devices and small electric appliance were recalled for electric shock risk, overheating problem and fire risk.

Infringement of patent rights is a frequently applied technical barrier by the US to exports from developing countries. There are large quantity and different types of Chinese products excluded and banned by 337 investigations. The banned products mainly include electronic device, such as semiconductor devices, mobile devices with multifunction emulators, balanced armature devices, rotating 3D LiRAD devices, filament light-emitting diodes, electronic nicotine delivery systems, earpiece devices, automatic vacuum cleaning device, etc. Other products include child carriers, child resistant closure with slider devices, medical supplies and clinical appliance, portable furniture, toner cartridges, carburetors, food process equipment, etc.

\subsection{Technical Barriers to Trade in Other Countries}

Technical barriers to trade applied by Japan to Chinese exports are mostly in the industries of agricultural products, textiles, chemical products and metal products. The special feature of technical barrier in Japan is that the political tension between Japan and China coincides with trade tension. The strict enforcement of SPS standard caused trade tension in agricultural products. Various Chinese food products are detained by Japanese custody, which include seasoning powder, dried fruit, dried vegetable, frozen vegetables, frozen seafood, fresh vegetable, rice, fried food and nutrition supplement. Recalled products by Health Canada include various export products from China. Product safety is one of the reasons for recall, such as fuel bottle, climbing device, sport helmet, trampoline, bicycle, baby cribs and cradles, desk, power adapter, which covers various industries. Other products are banned for safety concerns, for example, children's toys, clothes and other baby products for chocking risk; laptop, emergency starting power supply, electric heater and portable power source for fire risk; toasters for electric shock risk; wireless charger for burn risk; cosmetics for toxic substance; coffee maker, cup and glass pendant lamp for cutting and falling risk. In Austria and New Zealand, some food products from China, such as fruit products, nut products, snacks, frozen food, seasoning and seafood, were recalled by Food Standards Australia New Zealand (FSANZ) for the following reasons: contained foreign subject, contained metal, incorrect report of allergy source, chemical pollution, microbiology contamination, etc.

\section{IMPACT OF TECHNICAL BARRIERS AND COPING STRATEGY}

\subsection{Impact of Technical Barriers to Trade}

Technical barrier to trade could lead to trade tension between trade partners, and mutually enforced technical barriers would hinder international trade and reduce welfare in both countries. Technical barrier to trade would lead to increased domestic price, increased domestic production and net loss of social welfare. For a large sized economy, apply technical barrier on its import gods could improve term of trade. A small sized economy taken measures of technical barrier to trade would not be affected by term of trade effect. Trade barriers in general would disturb market distribution of resource and have a negative effect on economic growth. The discrimination feature of technical barriers could lead to further distortion of trade, output and welfare. 


\subsection{Coping Strategy}

Technical barrier could be more disguised than other forms of trade barrier, which makes it more difficult to recognize and response for exporters, and could be discriminating. To cope with technical barriers, early warning system could be established for exporters, to quantify non tariff barrier with tariff equivalent evaluation methods. Legal support should be provided for compliance with various standards in different trade destinations pre-trade, and for trade remedy cases after-trade. Legal expertise is in urgent need, which calls for human resource cultivation. For example, legal expert could help in trade arbitration and risk assessment in due diligence investigation. As for patent right barriers, technical expertise would be required to tackle more complicated patent right problems. For food safety and other product safety concern, a constant monitoring system should be established for product quality regulation, which could enhance competitiveness of Chinese export products to mitigate technical barriers and facilitate overseas trade.

\section{CONCLUSIONS}

Technical barrier to trade is increasingly frequent for Chinese export, than tariff barrier or traditional non-tariff barrier, such as anti-dumping and anti-subsidy measures. This paper analyzed different types of technical barriers in different industries. For the reason of food security, agricultural export from China encountered technical barriers in a number of developed countries, based on SPS and regulation standards stipulated by the authorities of import countries. Strategic industry, such as electronics and information technology, encountered intellectual property barriers. Manufacturing exports is under scrutiny for personal and health safety. This paper studied technical barriers in different countries. In European Union, RAPEX and RASFF hold higher standards than other regions. Chinese products are most likely to be denied entry for pesticide residual and choking risk. In the United States, FDA warned against certain food products, medical supplies and clinical appliances exported from China; CPSC recalled Chinese products for safety reason or quality problem; 337 investigations emphasized on infringement of patent rights. Lack of proper application for approval, rather than actual quality defect, is frequently applied by the US. Japan and other developed countries also recalled or notified warnings against manufacturing goods from China, especially Children's toys, clothes and other products for safety, and food products for pollution. The negative impact of technical barriers and its discrimination feature would lead to distortion of trade and welfare, which would impair economic growth. Coping strategies, such as risk warning system, legal expertise and technical support, cooperation amongst trade partners, could help mitigate technical barriers and facilitate international trade.

\section{ACKNOWLEDGMENT}

This research was financially supported by Hangzhou Normal University.

\section{REFERENCES}

[1] M. Ghodsi, How do technical barriers to trade affect foreign direct investment? Tariff jumping versus regulation haven hypotheses, Structural Change and Economic Dynamics, Vol. (52), March 2020, pp.269-278.

[2] Liu, F. Creutzig, Y. Yao, Y.Wei, Q. Liang, Environmental and Economic Impacts of Trade Barriers: The example of China-US Trade Friction, Resource and Energy Economics, In press, journal pre-proof, Vol. (59), February 2020, pp.101-144.

[3] T. Kompas, P.Van Ha, The 'curse of dimensionality' resolved: The effects of climate change and trade barriers in large dimensional modelling, Economic Modelling, Vol.(80), August 2019, pp.103-110

[4] R. Grundke, C. Moser, Hidden protectionism? Evidence from non-tariff barriers to trade in the United States, Journal of International Economics, Vol. (117), March 2019, pp.143-157

[5] F. G. Santeramo, E. Lamonaca, G. Nardone, A. Seccia, The benefits of country-specific non-tariff measures in world wine trade, Wine Economics and Policy, Vol. (8), Issue 1, June 2019, pp.28-37.

[6] D. Caldara, M. Iacoviello, P. Molligo, A. Prestipino, A. Raffo, The economic effects of trade policy uncertainty, Journal of Monetary Economics, Vol. (109), January 2020, pp.38-59.

[7] Q. Liu, L. D. Qiu, C. Zhan, Trade liberalization and domestic vertical integration: Evidence from China, Journal of International Economics, Vol. (121), November 2019, pp.103-125.

[8] F. S. Mandelman, A. Waddle, Intellectual property, tariffs, and international trade dynamics, Journal of Monetary Economics, Vol. (109), January 2020, pp.86-103.

[9] J. melo, J. Solleder, Barriers to trade in environmental goods: How important they are and what should developing countries expect from their removal, World Development, Vol. (130), June 2020, pp.104-110.

[10] K. J. McCarthy, On the influence of the European trade barrier on the Chinese pv industry: Is the solution to the solar-dispute "successful", Energy Policy, Vol. (99), December 2016, pp.154-157. 